\title{
APPLICABILITY OF BUILDING INFORMATION MODELING INTEGRATED AUGMENTED REALITY IN BUILDING FACILITY MANAGEMENT
}

\author{
S. Khan and K. Panuwatwanich* \\ School of Civil Engineering and Technology, Sirindhorn International Institute of Technology, Thammasat \\ University, Pathum Thani, Thailand \\ Emails: kriengsak@siit.tu.ac.th, sochea.itc@gmail.com \\ *Corresponding author
}

\begin{abstract}
Building Information Modeling (BIM) has played a significant part in streamlining the modern design, construction and project delivery of a building. BIM, when implemented properly, provides a flow-on benefits to the operation and maintenance phase of the building, enabling the facility manager to perform effective and timely asset management. Augmented Reality (AR) represents a latest addition to the visualization technologies used the construction industry, which has gained its omnipresence alongside the development of high-performance mobile devices. The ability to overlay digital information on to the real world allows users to merge the virtual environment with real world environment. In the construction context, this means the ability to visualize digital models over a real physical environment. By linking BIM with AR, the visualization can be greatly enhanced through the ability to see the digital information of the building overlaid on top of the actual physical building or the actual location of the building. The aim of the research presented in this paper is to examine the applicability of a BIM-integrated AR in the facility management of a building. As a case study, a BIMintegrated AR system is being developed for a selected part of a newly constructed laboratory building on a university campus. This system will be implemented and tested with the facility management team to evaluate its performance and practical usage for a wider implementation.
\end{abstract}

Keywords: Augmented Reality; Building Information Modeling; Digital Construction; Facility Management; Visualisation

\section{INTRODUCTION}

Building Information Modeling (BIM) is extensively used in countries-worldwide. It is rapidly gaining industry-wide adoption among the building industry and organizations involving in Architecture, Engineering, and Construction (AEC) as well as owners and operators of building projects (Kubba 2017).

Augmented Reality (AR) is known as the superimposition of a digital contents or computergenerated objects over a physical environment in the real world. In the past decade, AR has become very popular in gaming, market, and entertainment industries, and increasingly in other heavy industries including construction. Researchers have attempted to study AR technology to examines its current benefits and future potential in various fields (Wang et al. 2014).

The International Facility Management Association (IFMA 2019) stated that "Facility management is a profession that encompasses multiple disciplines to ensure functionality of the built environment by integrating people, place, process, and technology". Facility management provides a supportive role or 
service to the organizations in order to effectively manage and maintain buildings, people, assets in organization; and increase/cost efficiency. The importance of an effective facility management cannot be overlooked because it plays such an important role in the effectiveness of successful business.

This proposed study will achieve the below objectives:

1. To investigate the current practice of the building facility management in Thailand,

2. To examine the applicability of BIM-integrated AR in the building facility management,

3. To develop a conceptual BIMAR system for building facility management.

\section{LITERATURE REVIEW}

\subsection{Facility Management (FM)}

Facility management (FM) is the integration of people, place, process and technology within an organization to maintain and develop the agreed services which support and improve the effectiveness of its primary activities. It is an effective form of outreach business management which aims to provide relevant, cost-effective services to support and optimize the working activities (IFMA 2019).

Facility managers (FMs) are responsible for making sure systems of the built environment, or facility, work, harmoniously. They could have many different titles, but they share common roles within their respective organizations such as building operation and maintenance, sustainability, risk management, communication, performance and quality, project management, etc. Based on experiences, facility managers are able to define the requirements for the use of the future operational costs. Facility manager indicates a limited functional program of the building's space usage from the perspective of users. As, some parts of the building concerns about the future maintenance and repairs, details of the structure and equipment necessary for the technical support are needed. Facility manager in co-appointment with the investor and designers characterizes the requirements for the building from the perspective of users, and this can help reduce the costs and better achieve building services for the users (Potkany et al. 2015).

Chotipanich (2002) studied facility management practices in Thailand and found that facility management services mostly involve building operations, maintenance and routine services. Strategic facility management, planning and consulting services are being used at the minimum levels. More, the development of facility management practice is hindered by the attitudes of building owners who regard their own physical resources as risky, burdensome obstacles to daily work. Physical resources have a low priority in most organizations. Decision-makers take a short-term view of investments in construction and set close limits on budgets for maintenance and operation costs. The author concluded that facility management in Thailand appears to take place on operational levels. Many facility managers are constrained by their own business culture from trying to imagine their mission in a broader scope. In short, facility management practice in Thailand has been adapted and implemented in line with constraints of local knowledge, technology, investment and cultural preferences (Chotipanich 2002).

\subsection{Building Information Modeling (BIM)}

Building Information Modeling (BIM) is described by international standards as "shared digital representation of physical and functional characteristics of any built object which forms a reliable basis for decisions". BIM is an intelligent 3D model-based process that gives architecture, engineering, and construction (AEC) professionals the insight and tools to more efficiently plan, design, construct, and manage buildings and infrastructure. BIM does not only contain geometries, it also includes spatial connections, light investigation, geographic data, and objects' properties of building (Volk et al. 2014). 
Gao and Pishdad-Bozorgi (2019) examined 177 journal papers pertaining to BIM for facility management and divided them into 6 categories: maintenance and repair, energy management, emergency management, change/relocation management, security, and facility operation and management in general (Gao and Pishdad-Bozorgi 2019). Especially for maintenance and repair, a detailed area needed to discuss are: understanding the current practice and information source; data exchange and system integration; data accessibility; and fault detection and diagnosis. Furthermore, BIM has a potential in improving facility operation and management activities and providing new functionalities for facility managers, such as $3 \mathrm{D}$ visualization, comprehensive analysis, and real-time building information access.

\subsection{Augmented Reality (AR)}

Augmented Reality (AR) is a technology that superimposes a computer-generated image on a user's view of the real world, thus providing a composite view. It's an enhance of a virtual environment with the computer-generated object that the users can see in their view. A few classifications of augmented reality exist: Marker-Based AR; Marker-less AR; Projection-Based AR; and Superimposition-Based AR.

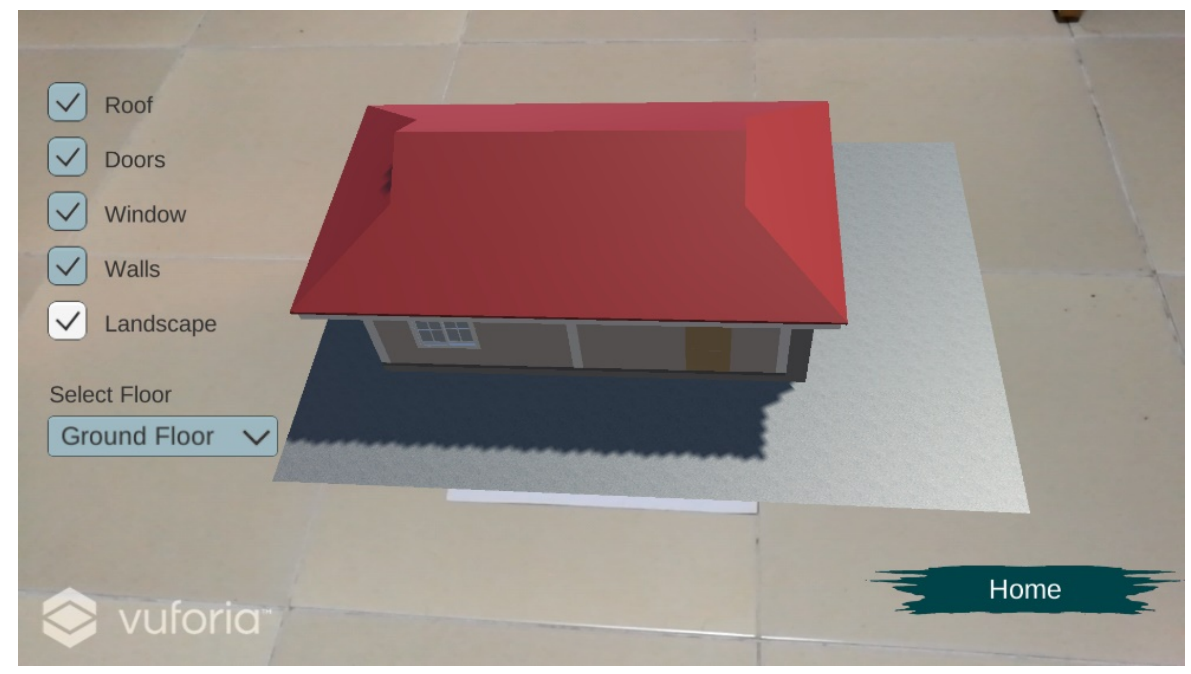

Figure 1. Augmented Reality example of a BIM model of a house projected on an image target.

AR is being used in different sections of a construction project. It is believed that AR technology is the latest technology with great potential to assist with the completion of certain tasks faster in the construction project (Ahmed 2018).

Since AR enables users to strengthen their perspectives with real-time superimposed digital information. User is able to use information about asset or to access step by step instructions on how to repair an asset while literally working with that asset. The AR system in maintenance has a lot of potential with the ability to receive information about specific assets. Using AR in maintenance work would gain many benefits such as reduced human errors, time, cost, and improved productivities. For example, company can utilize AR to provide written instructions on top of assets, reducing the number of hours spent on-boarding new employees.

Baek et al. (2019) applied AR-based system for facility management using the image-based indoor localization. The article proposed a system which is used to visualize pipe system in the building with the location onto the real scene to assist with site comprehension. The method also included indoor localization using TCP/IP to help in retrieving image. Thus, it demonstrated the applicability of the system in an actual building in a facility management 
scenario. The experts participated in the study tested and evaluated the system in facility management and agreed that the AR visualization is an effective approach that can be employed to facilitate communication among people related to the work as well as onsite personnel (Baek et al. 2019).

\section{METHODOLOGY}

This research intents to integrate Building Information Modeling (BIM) and Augmented Reality (AR) system deployed on a mobile device to improve building facility management. To fulfill this aim, research procedures, the development workflow of BIM integrated AR application, and preliminary work are proposed in the following sections.

\subsection{Proposed Research Procedures}

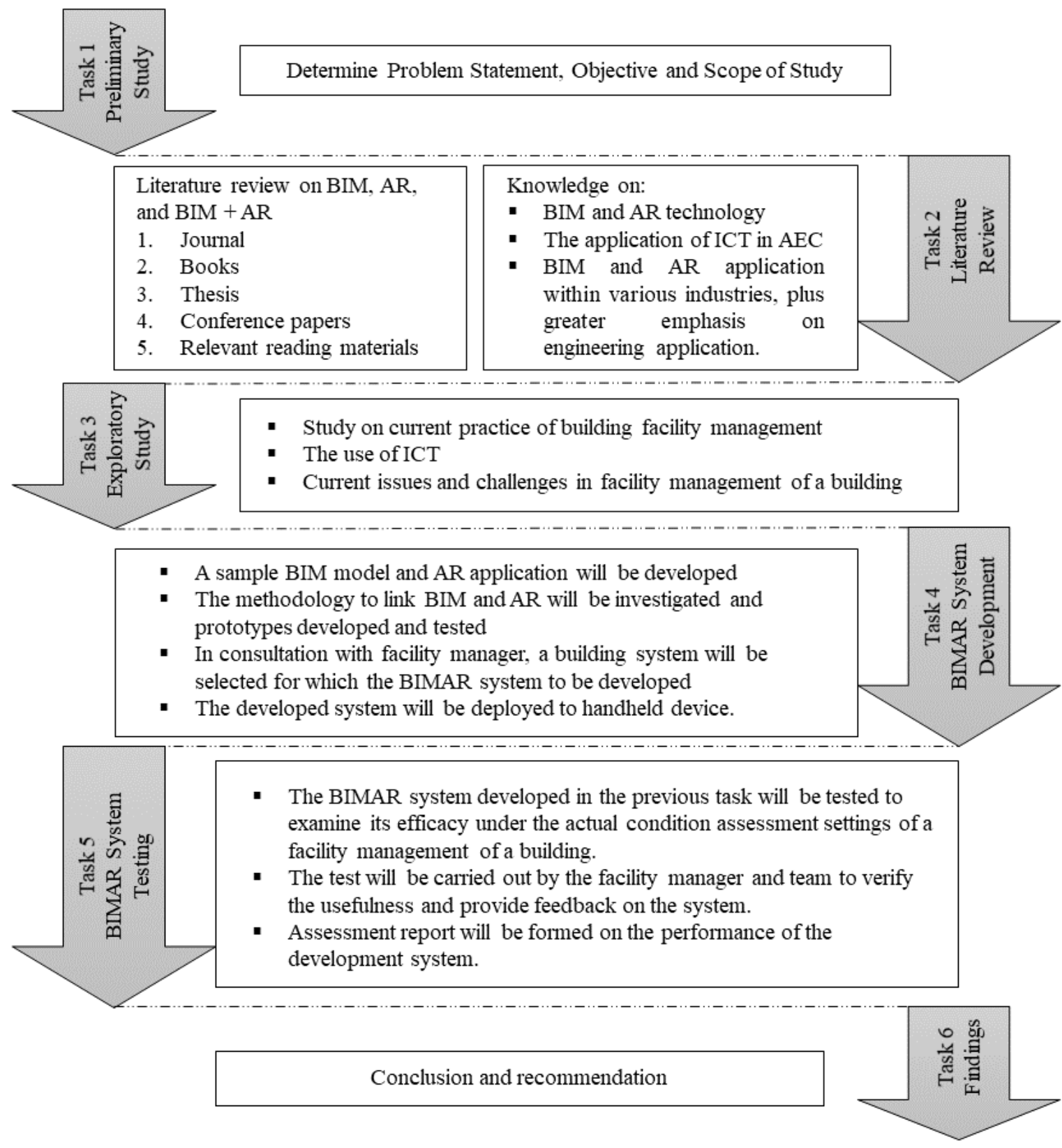

Figure 2. Proposed flowchart of research methodology. 


\subsection{Development Workflow of BIMAR Application}

The BIM-integrated AR system will be developed base on 3 main parts: 2D \& 3D asset creation, BIMAR system development, and BIMAR system deployment.

- The first part provides 3D BIM model developed from 2D CAD drawing and export to .fbx for the application. It is imported to process the model in 3D studio max first for the segment and material alignment (because Unity only recognizes textures or color from 3D studio max, not the existing from Revit) and then export the model to make it ready for the application as a final .fbx file.

- The second part is the designing stage of the system menu, and interactions between the users and the application. The scripts will be attached to the objects and buttons for users to be able to select and link to various functions of the system.

- The final part is the deployment of BIMAR system. The system will be saved as a .apk file and ready to install and used on a mobile (Android) device.

To understand more clearly how BIM-integrated AR system will be developed to achieve the research goal, Figure 3 below illustrates the development process.

2D \& 3DASSET CREATION

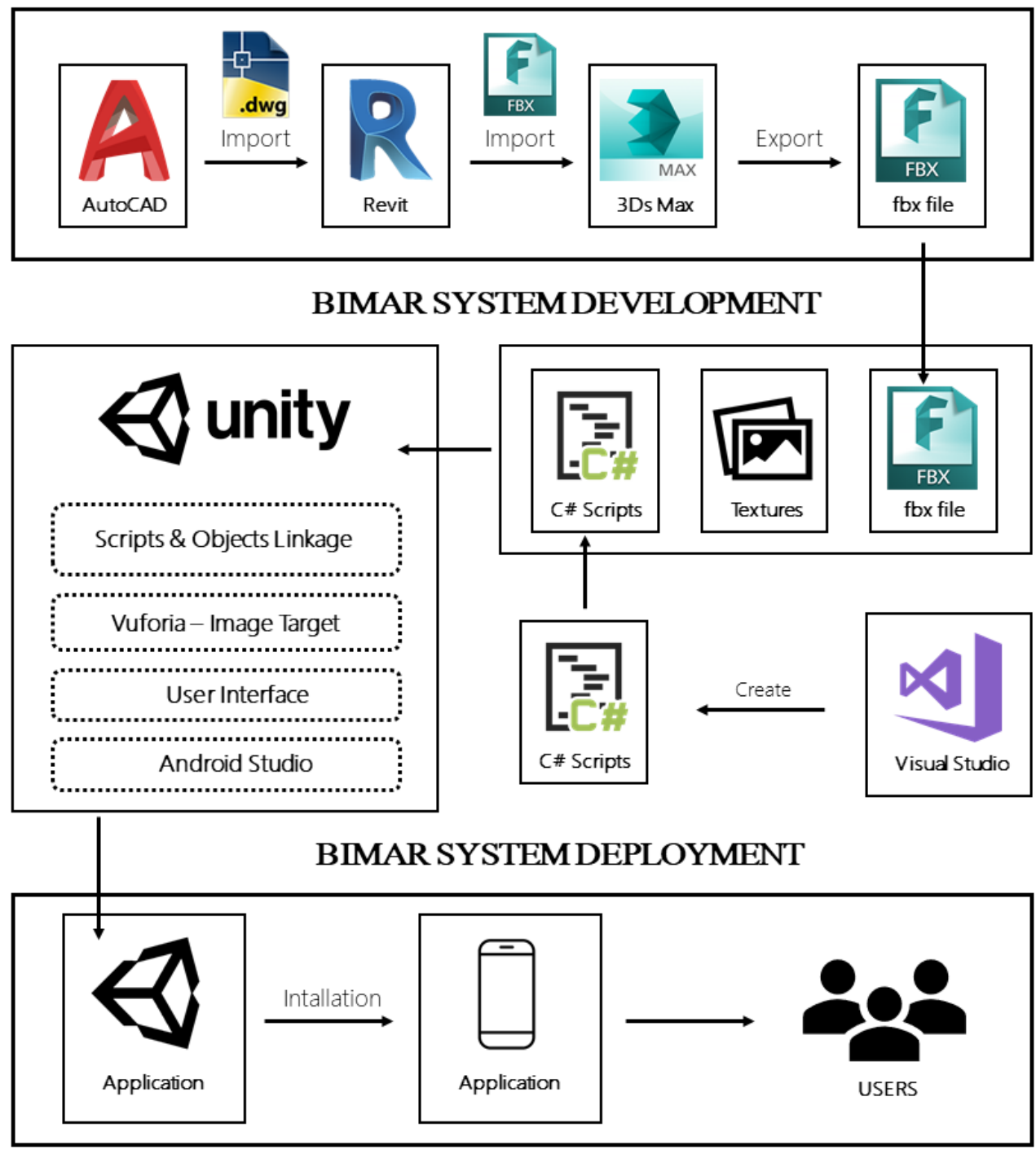

Figure 3. Proposed development workflow of BIMAR development. 


\subsection{Research setting}

In this study, a newly constructed laboratory building at Sirindhorn International Institute of Technology (SIIT), Thammasat University, Thailand, will be used as a test subject for the developed BIMAR system. Due to the lack of a BIM model for this building, a BIM model was created from 2D CAD drawings. Thus, the MEP system of a selected room inside the building will be used as a test model for the participant to experiment with how AR could help assist the building facility management team.

\subsection{Research tools}

The BIMAR system will be developed through software and plug-ins as listed: Unity (Game engine), Vuforia, Microsoft Visual Studio, Android Studio, Autodesk Revit, Autodesk 3D Studio Max, and Autodesk CAD. Plus, the hardware used for BIMAR system: an android device "Samsung Galaxy Note 9" and a gaming/design laptop “Asus ROG G501 JW".

\section{PRELIMINARY WORK}

\subsection{BIMAR system development}

Through the proposed workflow of BIM-AR system development, a sample BIM model was created from 2D CAD drawing using Autodesk Revit. It was exported to .fbx file to be used for the application development on Unity.
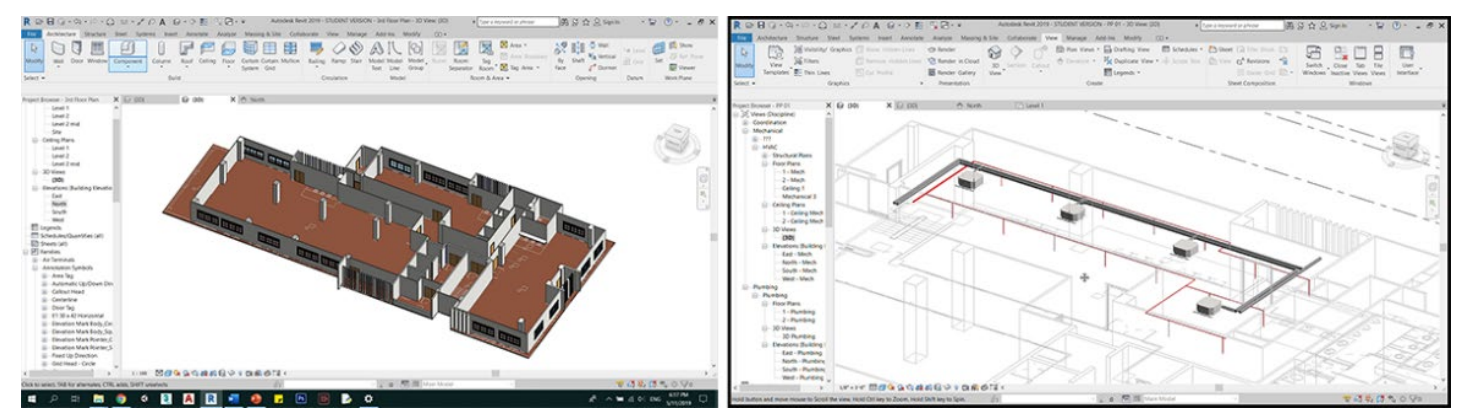

Figure 4. BIM model in Revit.

A BIMAR system was developed and deployed to a mobile device running an Android operating system. A pipe system was used as a sample in the developed BIMAR system that can be visualized through scanning an image target. An interface of the system was designed with clickable button function that is linked to each scene in unity to switch from one to another. Moreover, there is a function inside the image target that allows user to view a full model or just a specific part. Besides, user could find object's information by just clicking on the model. The information of a selected object will be shown on the right side of the screen. Figure 5 shows the sample of the developed BIMAR system that was developed to visualize a pipe and air-conditioning system as a sample prototype. 

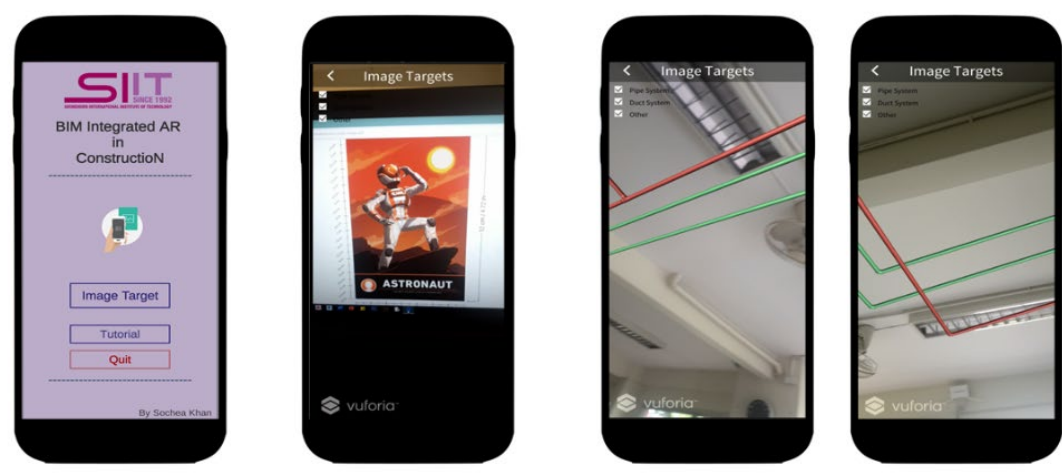

Figure 5. Screenshots of BIMAR system used to visualize an MEP model.

\subsection{Exploratory study}

To implement the system with the existing building, an exploratory study was conducted to understand a baseline situation of the current building facility management practice of the selected laboratory building. An interview with the building and ground division's staff of SIIT was conducted to gain some information about the current practices. It was found that a preventive maintenance was being used to operate the building to maintain serviceability and efficiency, which consists of the following activities:

1. Inspection: daily/monthly/yearly check due to its lifetime.

2. Cleaning: clean/clear dust/something that stick with object and make it work better.

3. Repair or replace: fix small issue by repair or replace some part before the whole system breakdown.

In the inspection part, paper-forms of inspection will be printed out to record the work. After that, there will be another request-form for the replacement if there is a part needing replacement. All data records are in a paper-based format and stored in folders that are kept at the office.

\subsection{Expected BIMAR system}

The BIMAR system will be experimented with a new lab building at SIIT. It would help the team to visualize the pipe system, check for its information, make a record, and save the data to the online database system by using a mobile device. It would help the team to save time, reduce papers, and improve productivity.

The prototype of the BIMAR system will be experimented by staffs of Building and Ground division of SIIT, who is currently working as a facility management team. The prototype will focus on the sprinkler and aircon system of a room in the newly constructed laboratory building. Before the test, participants will be guided to understand how the utilize of the BIMAR system. During the test, the participants will be able to use the application to visualize the digital model on a real environment by scanning the target attached to a specific position in the room. They could choose to see the model of the whole system or a specific part, and also an information panel when the participants click on the AR model. After getting to see the digital model on the real physical building and its information (properties, maintenance history, supplier, etc.).

After the test, the participants will be asked to complete a questionnaire about the usability of the developed system including its usefulness, information, and interface quality of the application. Feedback will be taken to determine the participants' satisfaction of the BIMAR system as well as any recommendation for further improvement. 


\section{CONCLUSION}

BIM is a useful concept that has been widely adopted in the construction industry as a tool to enhance collaboration and project delivery, including facility management. Augmented reality is a technology that can be used to overlay BIM model onto the real world. In facility management, visualizing the exact model on the exact location within the real-world environment is very important to better understand the parts requiring maintenance and to retrieve important information such as its service life, past maintenance records, suppliers, etc. By integrated BIM with AR, a system has been proposed and developed to be used to improve the work in the building facility management. A study was conducted to investigate the current practices of building facility management within a university campus in Thailand, as an experimental case. Six research tasks have been proposed to develop and test a BIMAR system. By capitalizing on the BIM and AR technology, it is expected that the developed system will help the facility management team to improve their work efficiency and productivity.

\section{REFERENCES}

Ahmed, S., (2018), A review on using opportunities of augmented reality and virtual reality in construction project management, Organization, Technology and Management in Construction: an International Journal, 10 (1), 1839-1852.

Baek, F., Ha, I. \& Kim, H., (2019), Augmented reality system for facility management using imagebased indoor localization, Automation in Construction, 99 18-26.

Chotipanich, S., (2002). Principles and concepts of facility management in thailand. note for presentation in FM Thailand Seminar 2002,. Chulalongkorn University, Bangkok.

Gao, X. \& Pishdad-Bozorgi, P., (2019), Bim-enabled facilities operation and maintenance: A review, Advanced Engineering Informatics, 39 227-247.

IFMA., (2019), What is facility management? [Online]. Houston, USA. Available: https://www.ifma.org/about/what-is-facility-management [Accessed 2019].

Kubba, S., (2017), Building information modeling (bim). In handbook of green building design and construction.

Potkany, M., Vetrakova, M. \& Babiakova, M., (2015), Facility management and its importance in the analysis of building life cycle, Procedia Economics and Finance, 26 202-208.

Volk, R., Stengel, J. \& Schultmann, F., (2014), Building information modeling (bim) for existing buildings - literature review and future needs, Automation in Construction, 38 109-127.

Wang, J., Pour Rahimian, F., Ibrahim, R., Wang, X., Shou, W. \& Xu, B., (2014), Integrating bim and augmented reality for interactive architectural visualisation, Construction Innovation, 14 (4), 453 476. 